\title{
Competition and Forecasts for Nobel Prize Awards
}

\author{
THEODORE MODIS
}

\begin{abstract}
The evolution of Nobel prize awards is studied as a leaming/growing process. A simple logistic function describes the data well and accounts for the competition, be it between individuals or between nations. The American niche appears to be $64 \%$ exhausted by 1987 , implying a diminishing expected rate of laureates in the future. Europeans have been losing ground continuously from the beginning while the remaining world has recently received more awards. Projections to the year 2000 and beyond are given. Correlations with age support the Darwinian nature of the competition for Nobel prizes. Awards to women show peaks coincidental with outbursts of feminism.
\end{abstract}

\section{Introduction}

Nobel prize awards constitute the ultimate criterion of excellence in our century. Every year the Nobel foundation in Sweden painstakingly searches the entire world for the most outstanding contributors to the benefit of humanity. They do their work as impartially as they can consciously be and often in spite of political pressures and influences.

On the other side, the world's most exceptional specialists, often brilliant and aspiring individuals, hope for and sometimes willingly compete fiercely for this outstanding distinction. Institutions and countries pride and measure themselves with the number of Nobel laureates they can count and occasionally pressures mount for Nobel awards thought overdue. As in the Olympic games, laureates return home as national heroes.

In this work, the competition for Nobel prizes is looked at as Darwinian in nature (logistic growth). The work was stimulated by the impressive number of American laureates in recent years and by C. Marchetti, who first pointed out the American Nobelprize niche to me [1].

\section{The Decline of the American Empire}

Growth under competition has been mathematically described by a logistic function:

$$
P(t)=\frac{\operatorname{Max}}{1+e^{-\alpha\left(t-t_{0}\right)}}
$$

THEODORE MODIS is an experimental high energy physicist and has carried out research experiments for over 15 years at CERN, in Geneva, Switzerland, at Brookhaven National Laboratory Upton, New York, and at Nevis Laboratories, Irvington-on-Hudson, New York. He has also been on the teaching faculties of Columbia and Geneva Universities. 


\section{AMERICAN NOBEL PRIZE WINNERS (CUMULATIVE)}

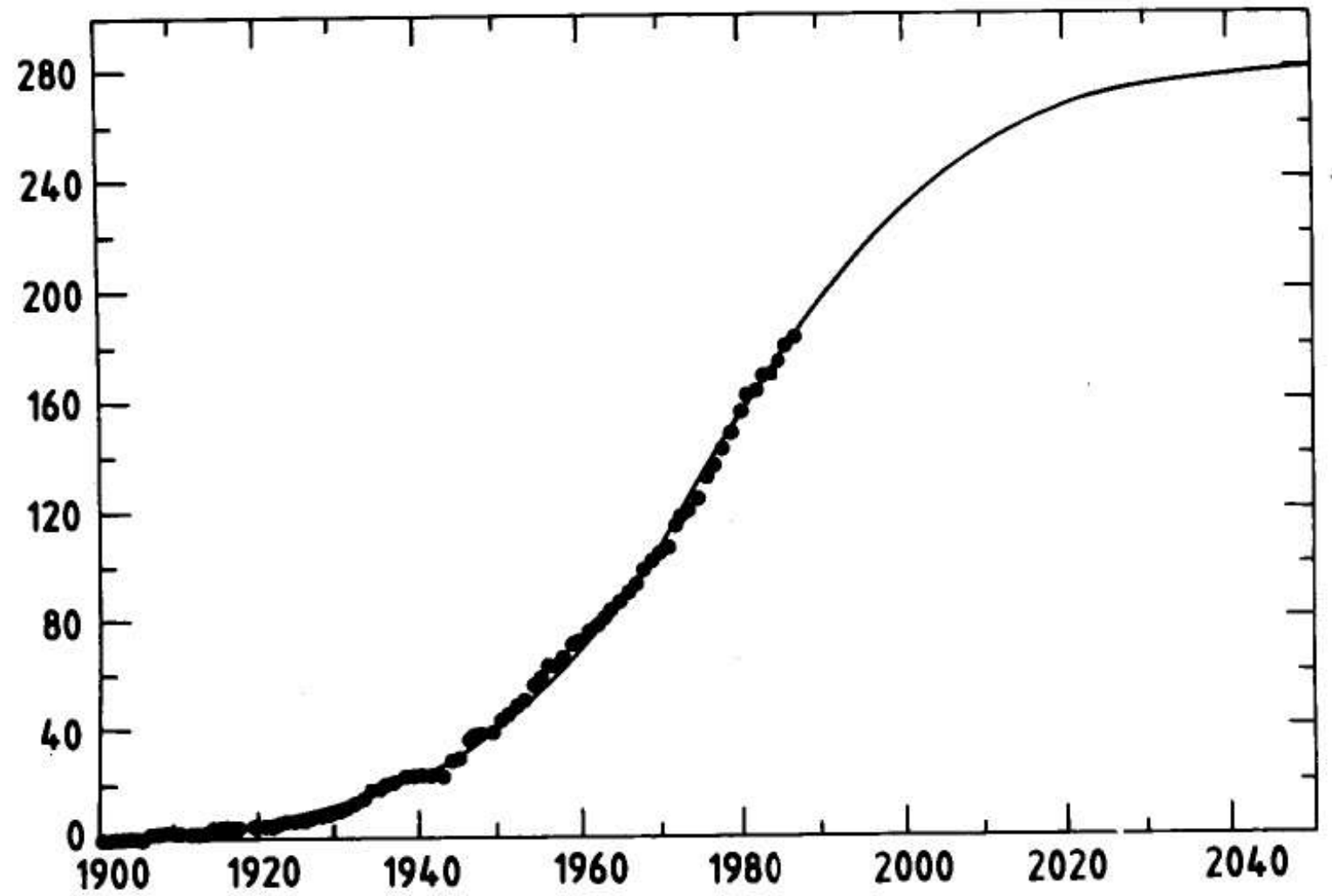

Fig. 1a. American Nobel laureates. Cumulative data and logistic fit, the niche capacity is fitted as 283. The actual number of 182 makes the niche $64 \%$ exhausted.

where Max, $\alpha$, and $\mathrm{t}_{0}$ are constants.

Equation (1) is the solution to the differential equation that says that the percentage rate of a population growth under competition is proportional to the remaining amount of growth. Obviously a final maximum Max, a potential, is understood to be associated with the filling-up of every niche. Numerous applications of logistic growth during the filling-up of niches abound in the literature. For some varied examples see references [2-4].

Considering the United States as a niche for Nobel laureates, one can try to fit a three-parameter logistic to the cumulative number of American awards. If we take all disciplines together and count each individual as one-even if he/she only shared the prize with others-we obtain the result shown in Figure 1a. The agreement between the data points and the three-parameter logistic fit is impressive. The niche seems to be $64 \%$ exhausted by the end of 1987 . Today 182 Americans are listed while the total number of all Americans who will ever receive the Nobel prize is 283 .

Figure $1 \mathrm{~b}$ shows the yearly awards. The superimposed smooth line is the derivative of the function determined by the fit of Figure 1a. It shows that the maximum rate of awards, 4.5 per year, was in 1978 and that since then this number has been decreasing to reach 4.2 in $1987,2.9$ by the year 2000 , and 0.2 by the year 2050 . Obviously, it would have been far-fetched to conclude that a decline had already settled in 10 years ago just by looking at the raw data with their huge yearly fluctuations.

The question that immediately comes to mind is: "If Americans are winning fewer Nobels, who is winning more? To answer this we have to consider the percentage shares 


\section{AMERICAN NOBEL. PRIZE WINNERS (YEARLY)}

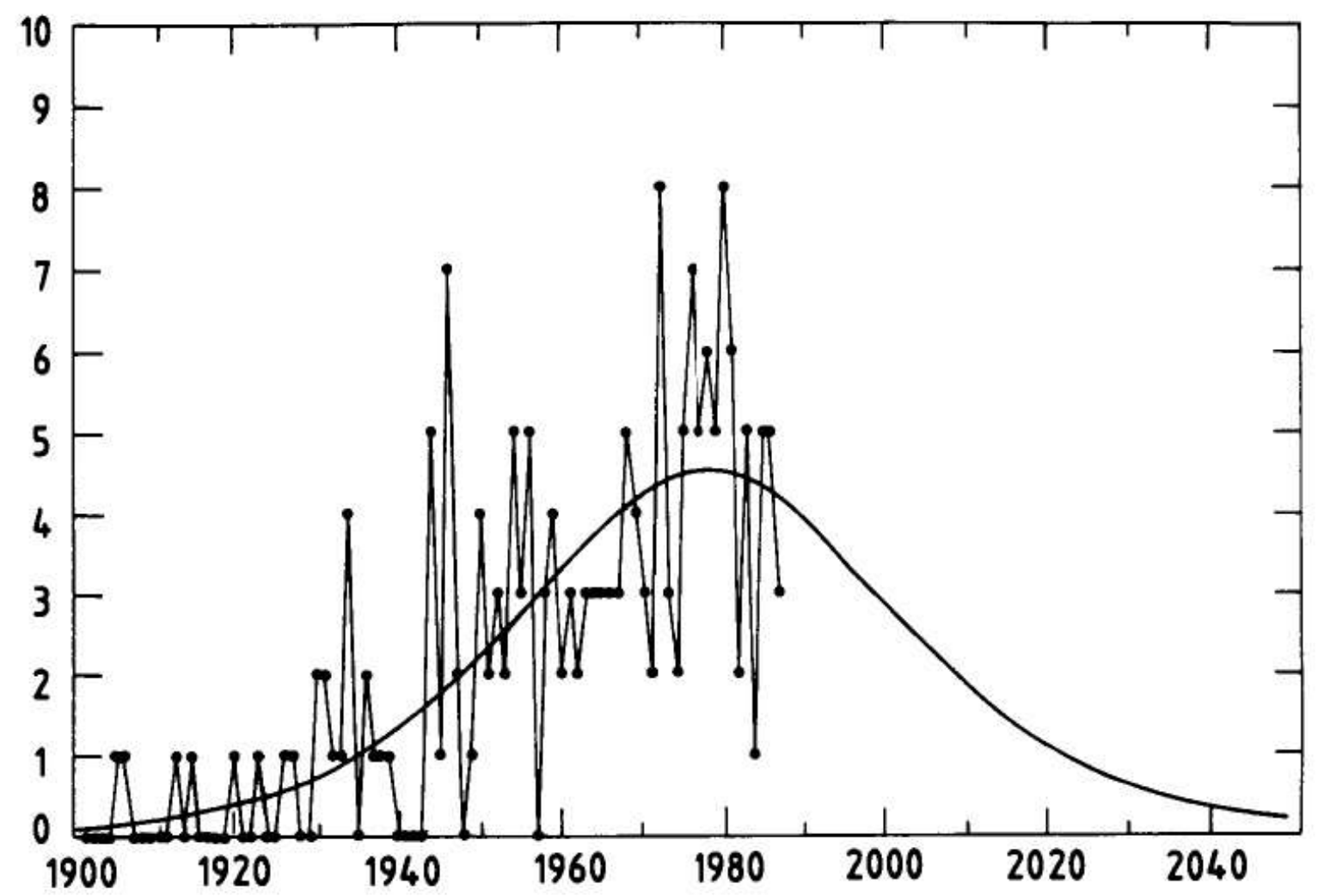

Fig. 1b. American Nobel laureates. Superimposed on the yearly awards data, dark circles, is the derivative of the logistic fit of Figure 1a, smooth curve.

of the competitors and look for logistic substitutions among them. In fact, doing this below, we see that the American decline is not as alarming as presented in Figure 1.

\section{Competition in the World Arena}

What is employed here is the generalized logistic substitution, in terms of market shares, of a number of successive competitors entering and existing a given market as developed by Nakicenovic [5]. In our case the market is the total number of Nobel awards per year and contenders are all the countries. Some 40 countries shared a total of 652 Nobel laureates by the end of 1987. A great many countries show a very small number of awards. Therefore, it was necessary to group countries together while looking for trends. The most successful and the most reasonable grouping comprised three regions. The United States is clearly one such region; "classical" Europe is another, consisting of France, Germany, Great Britain, the USSR, Italy, the Scandinavian countries, Belgium, Holland, Austria, Switzerland, Spain, and Ireland. The third group is formed by the rest, which may be called "Other World." It includes many third-world countries and many developing countries, but also some formidable competitors of the "West" such as Japan, Australia, and Canada.

This classification emerges "naturally," because when we plot the shares of the three groups as a function of time (Figure 2) we see typical logistic behavior. The share of classical Europe has been continuously decreasing. It was taken up by the United States until the second World War and by the Other World from then onward.

The United States made an impressive entry (steeper than the other logistic paths) 


\section{DISTRIBUTION OF NOBEL AWARDS}

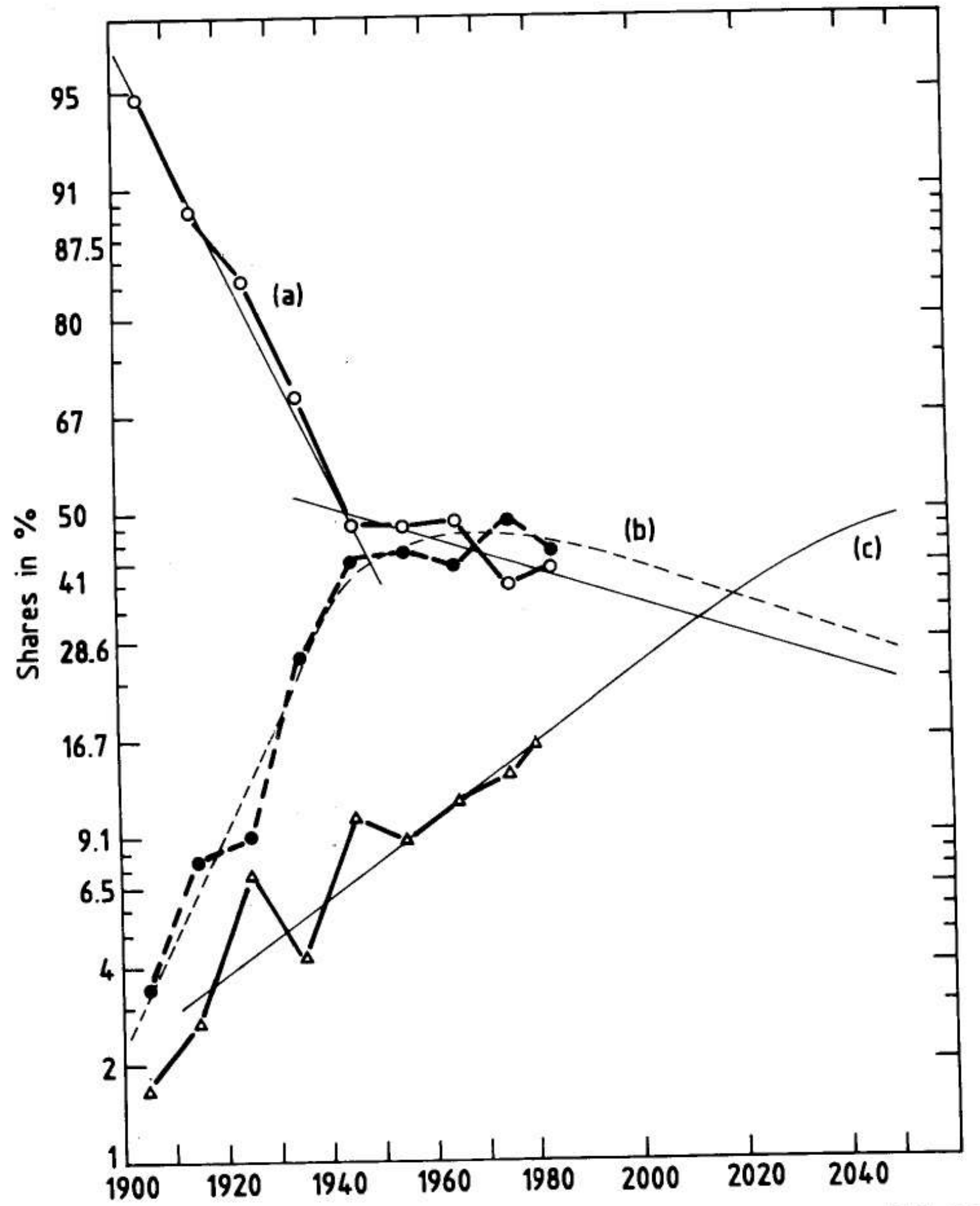

Fig. 2. Distribution of yearly Nobel laureates by the three groups: (a) classical Europe, (b) United States, and (c) Other World (see text). Ten-year bins.

but it practically reached a ceiling by the end of WWII. For the last 50 years the United States share has not been increasing. It is more the Other World that is on the rise during this time, again at the expense of Europeans. This substitution, however, takes place at a less dramatic rate than the one, before the war, between Americans and Europeans. Putting in straight lines (logistic trajectories) for the variable $\ln \frac{f}{1-f}$, where, $f$ is the fraction of a given group, provides a forecast (thin lines) in Figure 2. This shows that 


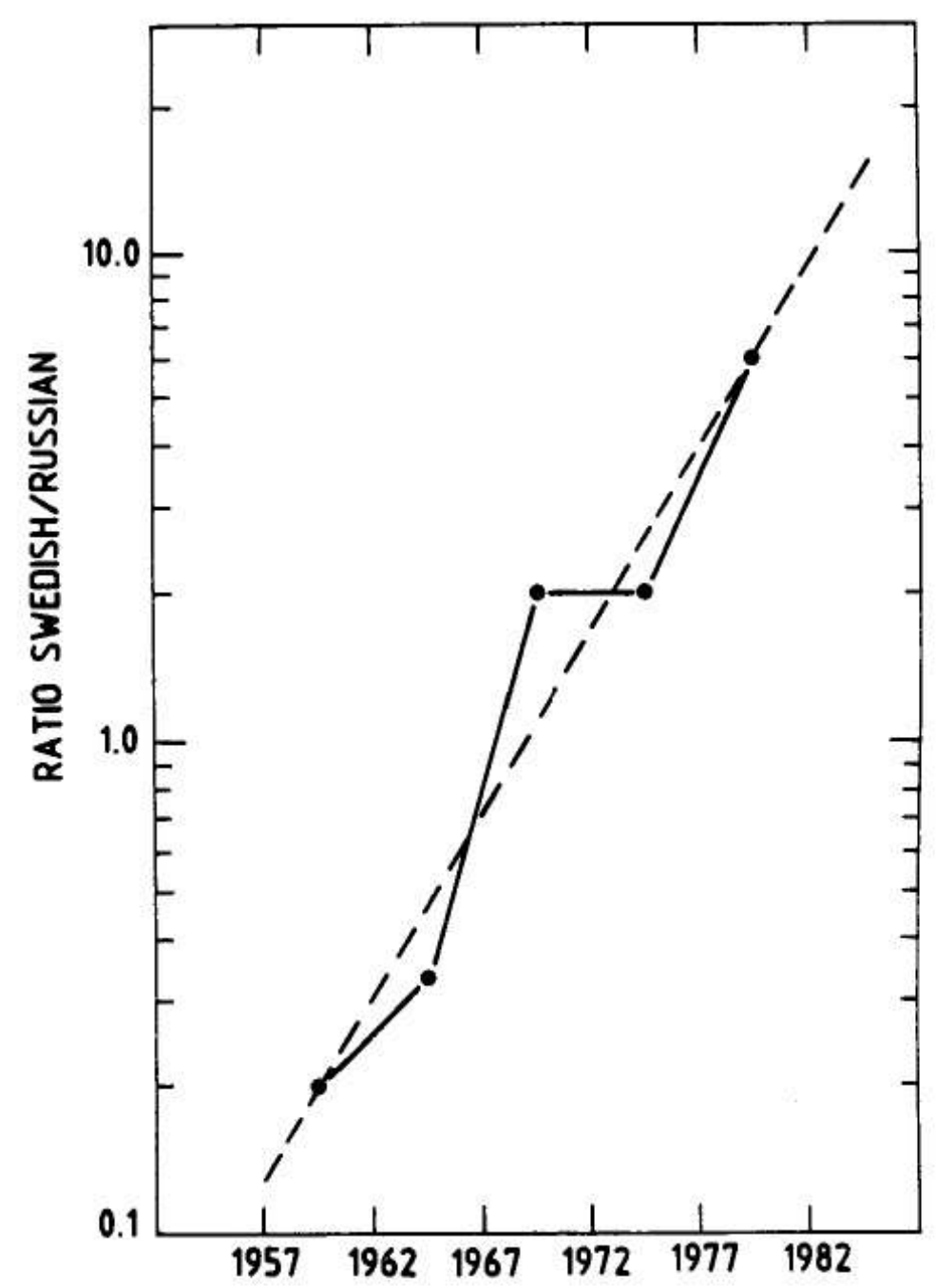

Fig. 3. The Swedish-Russian microniche; 5-year bins.

the Other World will overtake the Europeans in 2010 and the Americans in 2035. The United States will start losing its competitive advantage only in the year 2000.

Thus, despite the fact that the yearly number of laureates is already decreasing for the United States, decline in competitiveness has to be positioned after the year 2000 . If this is to be true, the overall number of Nobel laureates must also decrease in the future. This comes as no surprise when we look at section 6 below.

\section{The Swedish-Russian Microniche}

In the process of combining nationalities to unveil trends a striking and persisting detail was noticed. Between the years 1957 and 1982 the Russian share declined sharply while the Swedish one showed a sharp rise. The slopes being very similar make one suspect a one-to-one substitution in a local microniche.

Indeed, the sum of the laureates for both countries is remarkably constant, equal to five for all five of the 5-year intervals, and the ratio of Swedish/Russians on the logarithmic scale is quite compatible with a straight line (see Figure 3), a hallmark of logistic substitution. Can this be an artefact of statistical fluctuations? Could it be attributed to a subconscious bias considering that the Nobel committee is Swedish and that traditionally there has been some animosity between the two countries? Or can it be a natural logistic substitution in a local microniche?

Two arguments come to mind, and both stand against the third hypothesis: One is 


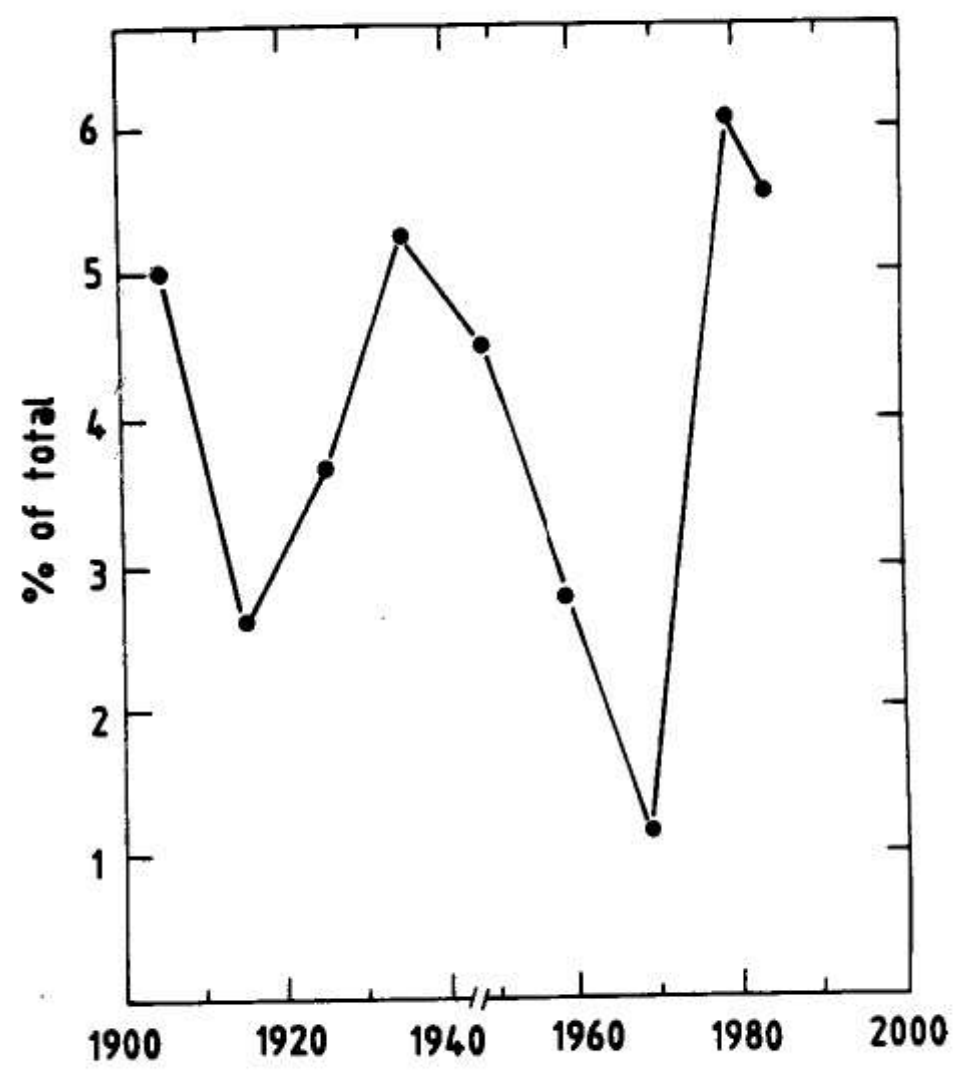

Fig. 4. Women laureates as percentage of the total. Typical error bars are between 2 and 3 percent.

based on relating competitiveness to age. The average age of the Swedish laureates is 65.1 , distinctly higher than the average Russian age of 57.5 during the same period. There can be no competitive advantage of a Darwinian nature as can perhaps exist for Americans over Europeans and, later on, for the Other World over the United States (see section 6 below). The second argument is the lack, to my ability, of justification for the definition of one niche out of Russians and Swedes together, and over that particular period of time between 1957 and 1982.

At any rate, considering that there have been no Swedish laureates during the last five years, we may have seen the end of this phenomenon, which may have been triggered by the unpopular intervention of the Russians in Hungary in late 1956.

\section{Women Laureates}

The percentage of women laureates is generally low. It hovers around 3 to 4 percent. However, as can be seen in Figure 4, there is a systematic variation. Error bars on the data points should be taken between 2 and 3 percent. There is a periodicity of about 50 years with outbursts in the 1930s and again in the late 1970 s to early 1980 s. It is perhaps not a coincidence that feminist movements peaked at the same time. Also the periodicity of about 50 years reminds us strongly of the cycles of 55 years put forth by Kondratieff [6] and later by Marchetti [7]. According to this reasoning the near future will see a smaller percentage of women laureates, with the next peak around 2030.

\section{The Future of Nobel Prizes}

We saw earlier that the number of American laureates per year is already decreasing, although their share will remain stable until the year 2000 . The implication of this is that the total number of Nobel laureates will also go down. Is it reasonable to expect that the institution of Nobel awards will weaken and wither with time? 


\section{TOTAL NOBEL AWARDS}

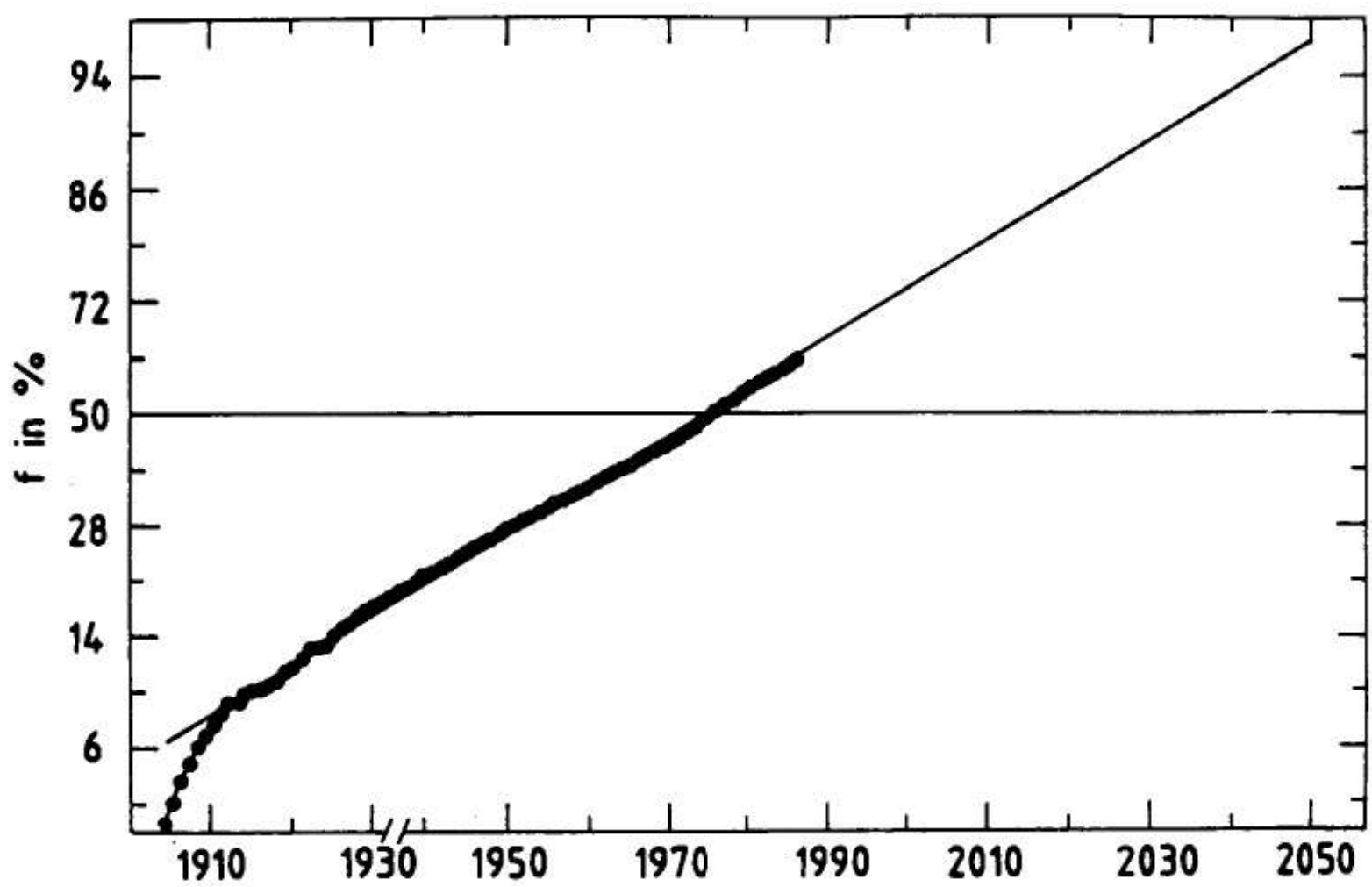

Fig. 5. The total number of Nobel laureates, cumulative. What is plotted is the variable $\ln \frac{f}{1-f}$, where $f$ is the fraction of the niche occupied at the time. The niche capacity is fitted as 923 . The vertical scale is calibrated to show $f$ in percent. The straight line is superimposed to guide the eye.

There are several observations that support such a hypothesis. The first is that the yearly number of laureates has been increasing. New categories are being added (e.g., economics, peace) and more individuals share prizes more often as time goes on. The increase in number of recipients cannot continue at a constant rate. Inflationary tactics leading to devaluation may suggest that at some point the rate of recipients per annum would flatten and indeed would start decreasing, the hallmark of niche filling.

A second observation is that the average age of Nobel laureates is increasing with time. It was 54.5 until 1940 , it has risen to 57.7 since 1940 , and if we look at the last 10 years only, it has reached 60 . Although this may in part reflect the general increase in life expectancy, it is degenerate in nature inasmuch as excellence is associated with the older and weaker rather than the younger and better fit for performance. It is worth noting that age does correlate with performance. The increase of the average age was not monotonic. Peaks of activity in awards where Americans distinguished themselves brilliantly in the 1930 s and the 1950 s have average ages of 51.1 and 49.1 , respectively, for these decades.

Furthermore, the competitive dynamics described by Figure 2 are in agreement with age advantages. The Americans were gaining on the Europeans up to 1940, with an average age of 52.9 versus 54.8 years. Similarly, in the last 10 years the Other World is gaining on the Americans with an average age of 57.3 versus 59.3 years, while Europeans continue losing with an average of 62.4 .

Youth, thus seems to have an advantage over old age, whereas the proliferation of awards at an increased age is indicative of reduced reason for existence. The argument 
is more relevant when we consider that the awards often follow the actual work with a long delay. The recipient's age at award time was considered here because it was readily available and because sometimes it is better defined than the date when the actual work was done. The relative age advantage, however, is unaffected assuming there is no systematic bias of this delay among the three regional groups considered here.

With all this in mind, one is tempted to see if the cumulative number of laureates itself follows a logistic growth. That is, if it is in the process of filling up a well-defined niche. Figure 5 shows the variable $\ln \frac{f}{1-f}$ where $f$ is the fraction of the niche already occupied. A straight line behavior would be indicative of a good logistic description [24]. Indeed, the straight line character of the data points is striking. The small deviation at the very low end, where $f$ is less than $5 \%$, is not surprising in logistic behavior.

It seems that the Nobel niche is just over half full with a world potential of 923 laureates over all time. The rate of laureates per annum shown in Figure 5 for the year 2050 can be calculated to be less than two. An independent determination of this rate for the year 2050 can be obtained from Figures $1 \mathrm{~b}$ and 2 . A yearly rate of 0.2 for Americans at a share of 0.25 implies a total rate of just under one per year. The two results are in good agreement. Seen from the periodicity of 55 years, one may say that the life-span of the Nobel institution is three times 55 years, i.e., about 165 years.

Another Mr. Nobel is perhaps somewhere in the process of brewing a new institution of awards that may, after all, be based on a different type of excellence than the one we have known so far.

The author thanks the Nobel Foundation, which kindly provided facts on a complete list of Nobel laureates.

\section{References}

1. Marchetti C. International Institute for Applied Systems Analysis, Luxembourg, Vienna, personal communication.

2. Fisher, J. C., Pry, R. H. A simple substitution model of technological change. Technological Forecasting and Social Change 3:75-88 (1971).

3. Marchetti, C. On the role of science in the postindustrial society. Technological Forecasting and Social Change 24:197-206.

4. Modis, T., Debecker, A. Innovation in the Compute: Industry. Technological Forecasting and Social Change, in press.

5. Nakicenovic, N. Software Package for the Logistic Substitution Model, R.R. 79-12. International Institute for Applied Systems Analysis, Luxembourg.

6. Kondratieff, W. D. The long waves in economic life. The Review of Economic Statistics, 17(6):105-115 (1935).

7. Marchetti, C. Swings, cycles and the global economy. New Scientist No. 1454:12-15 (1985). 